\title{
Respiratory syncytial virus prolifically infects N2a neuronal cells, leading to TLR4 and nucleolin protein modulations and RSV $F$ protein co-localization with TLR4 and nucleolin
}

Xiaoling Yuan ${ }^{1 \dagger}$, Tao $\mathrm{Hu}^{1 \dagger}$, Hanwen $\mathrm{He}^{3 \dagger}$, Huan Qiu' ${ }^{1}$ Xuan $\mathrm{Wu}^{1}$, Jingxian Chen ${ }^{1,4}$, Minmin Wang ${ }^{1}$, Cheng Chen ${ }^{5}$ and Shenghai Huang ${ }^{1,2^{*}}$

\begin{abstract}
Background: Respiratory syncytial virus (RSV) infects the central nervous system, resulting in neurological symptoms. However, the precise underlying pathogenic mechanisms have not been elucidated. In the present study, the infectivity of RSV on N2a neuronal cells and the possible roles of Toll-like receptor 4 (TLR4) and nucleolin (C23) during RSV infection were investigated.

Methods: We compared two experimental groups (infected and non-infected) and monitored the RSV viral titers in the culture supernatant by a viral plaque assay. We also inspected the morphology of the nucleus in infected N2a cells. We measured the level of RSV F protein and studied its co-localization with TLR4 and nucleolin using immunofluorescence assays and laser confocal microscopy. The potential interaction of RSV F protein with TLR4 and nucleolin was examined by coimmunoprecipitation. The expression changes of TLR4, nucleolin, TLR3 and TLR7 proteins in N2a cells and IL-6 and TNF-a in the culture supernatant were investigated by Western Blot analysis and ELISA assay. Changes in neuronal cell apoptosis status was examined by flow cytometry.

Results: The results demonstrated prolific RSV infection of N2a cells, which triggered a decrease of NeuN protein expression, coinciding with an increase of nuclear lesions, F protein expression, RSV viral titers, and late apoptotic levels of N2a cells. RSV infection induced co-localization of RSV F protein with TLR4 and nucleolin, which could potentially lead to a direct interaction. Furthermore, it was found that TLR4 and nucleolin levels increased early after infection and decreased subsequently, whereas TLR3 and TLR7 expression increased throughout RSV infection.

Conclusion: The RSV Long strain can prolifically infect N2a neuronal cells, modulating the expression of TLR4 and nucleolin, as well as TLR3, TLR7 and their downstream inflammatory factors, and inducing the co-localization of the RSV F protein with TLR4 and nucleolin.
\end{abstract}

Keywords: Respiratory syncytial virus (RSV), Toll-like receptor 4 (TLR4), Nucleolin (C23), Virus infection, N2a cells

\footnotetext{
*Correspondence: huangshh68@aliyun.com

Xiaoling Yuan, Tao Hu and Hanwen He are co-first authors.

${ }^{\dagger}$ Equal contributors

${ }^{1}$ Department of Microbiology, School of Basic Medicine, Anhui Medical

University, Hefei, Anhui Province 230032, People's Republic of China

${ }^{2}$ School of Life Sciences, Anhui Medical University, Hefei, Anhui Province

230032, People's Republic of China

Full list of author information is available at the end of the article
} 


\section{Background}

Respiratory syncytial virus (RSV), an enveloped, singlestranded, negative-sense RNA pneumovirus, is a member of the Orthopneumovirus genus and Pneumoviridae family. Inflicting high morbidity and mortality rates in infants and young children, RSV is the most important pathogen responsible for lower respiratory tract infections in infants worldwide [1].

Recently, RSV was found to infect the nervous system and induce neurological symptoms, such as drowsiness, convulsions and epilepsy [2, 3], which might exist chronologically or independently. In clinical cases, acute encephalopathy was associated with RSV infection, and approximately $40 \%$ of RSV-positive patients presented with acute neurological symptoms before the age of 2 years [4]. Although the viral RSV genome has been detected in the cerebrospinal fluid (CSF) of children presenting with RSV infection-related convulsions or central nervous system (CNS) symptoms [5], the molecular mechanism underlying RSV neuropathogenesis remains unclear. Neuronal abnormalities might directly induce encephalopathic symptoms, such as epilepsy, seizures, convulsions or lethargy, and long-term neurological sequelae, including cognitive impairment and seizures, have been observed in patients. Additionally, movement disorders have also been observed in patients who survived encephalitis induced by Japanese encephalitis virus (JEV) infection [6].

N2a cells, a rapidly growing mouse neuroblastoma cell line, were derived from a spontaneous tumor in an albino strain A mouse. Because N2a cells differentiate into cells possessing many neuronal properties in vitro and express neuronal markers, such as neurofilaments, they are commonly used for studying neurotoxicity, Alzheimer's disease, and neurotropic viruses, such as HSV-1 and rabies virus [7-10]. N2a cells have also been employed as a model system to study the CNS pathology of JEV-induced viral encephalitis, as they are permissive to this virus [11]. Thus, N2a cells were selected to study the characteristics of RSV infection in the current study.

Nucleolin (C23), a ubiquitous 105-kDa nucleolar protein expressed in exponentially growing eukaryotic cells, is a cell surface receptor for several ligands, including midkine, matrix laminin-1, attachment factor J, and lipoproteins apo-B and apo-E [12-15]. This phosphoprotein is found mainly in the nucleus, where it regulates cell proliferation and growth, embryogenesis, cytokinesis, and nucleogenesis [16]. More recently, C23 was proposed to mediate the extracellular regulation of nuclear events [14] and shown to play roles in inflammatory responses induced by lipopolysaccharides (LPS) [17]. Furthermore, reports have also suggested that surface C23 may serve as an attachment target for some viruses, such as $\operatorname{HIV~}[18,19]$. Based on its relative molecular mobility during sodium dodecyl sulfate-polyacrylamide gel electrophoresis (SDSPAGE), C23 is often described as a $100-110-k D a$ protein, although its putative molecular weight is approximately $78 \mathrm{kDa}$ [20]. Tayyari et al. reported that C23 acts as a cellular receptor to recognize the RSV F protein, and interfering with the C23-RSV F protein interaction inhibits RSV infection in cell cultures and in animal models [21]. These finding are consistent with the characteristics of other enveloped virus cellular receptors, such as those of herpes simplex virus [22] and hepatitis B virus [23].

Toll-like receptors (TLRs) play essential roles in innate immunity and are expressed in a wide range of cell types, including CNS cells. TLR engagement by specific sets of microbial ligands trigger the production of proinflammatory factors and enhance antigen-presenting cell functions. However, the functional roles of TLRs in the CNS are poorly understood [24]. Purified RSV F protein elicits an inflammatory response in hematopoietic cells, requiring the expression of TLR4 and its coreceptor CD14. While TLR4 expression is known to play an important role in controlling RSV replication [25], its biological role in immune responses to RSV remains inconclusive and controversial $[26,27]$.

F protein is a surface protein on RSV virions that mediates fusion of the virus membrane with that of the host cell, enabling RSV to enter cells and synthesize new F proteins in the infected cells [27]. Therefore, the RSV F protein plays a vital role in the pathogenesis of RSV infection. Kurt-Jones et al. reported that separate viral products, such as purified RSV F protein, might bind TLR4 and/or CD14, but no direct evidence supporting an interaction between intact RSV particles and the TLR4 receptor complex during the course of RSV pathogenesis have been reported [25].

Because neuronal cells express TLR4 and C23 [28, 29] and TLR4 and C23 are capable of recognizing the RSV F protein, we tentatively hypothesized that RSV might enter neuronal cells via interactions of the F protein with TLR4 and $\mathrm{C} 23$, resulting in the proliferative infection of $\mathrm{N} 2 \mathrm{a}$ neuronal cells. Thus, in this study, the ability of RSV Long strain to infect N2a neuronal cells was investigated, and the relationships between TLR4 and C23 expression and the RSV F protein in N2a cells were explored. In addition, because TLR3/TLR7 might recognize double-stranded RNA and the single-stranded RNA genome during RSV replication, TLR3/TLR7 variations were also studied in RSV-infected N2a cells. Hopefully, our study will help elucidate new therapeutic targets for the prevention and control of human RSV-associated encephalopathy.

\section{Methods}

\section{Cells and viruses}

N2a neuronal cells (a gift from Prof. Yu-Xian Shen, Anhui Medical University, Hefei, China) were cultured in DMEM 
(Dulbecco's Modified Eagle's Medium, Life Technologies Corp, USA) supplemented with $10 \%$ fetal bovine serum (HyClone, USA) and 1\% penicillin (100 U/ml)-streptomycin $(100 \mu \mathrm{g} / \mathrm{ml})$. The cells were incubated in a humidified atmosphere comprising $95 \%$ air and $5 \% \mathrm{CO}_{2}$ at $37{ }^{\circ} \mathrm{C}$.

RSV Long strain (a gift from Dr. Hai-Ming Wei, Institute of Immunology at the University of Science and Technology of China, Hefei, China) was propagated in HEp-2 cells, and viral stocks were purified and stored in liquid nitrogen. Viral titers were determined using a modified methylcellulose plaque assay as described by Kisch et al. [30] using confluent HEp-2 cells grown on 12-well plates (Corning Inc., USA). For the experimental infections, N2a cell monolayers were infected with RSV at a multiplicity of infection (MOI) of 2 in 24-well cell culture plates (Corning Inc.).

Similarly, RSV viral titers in N2a cells were determined by a modified plaque assay [30]. Briefly, N2a cells were first seeded in 12-well tissue culture plates at a density of $5 \times 10^{4}$ cells per well in high-glucose DMEM supplemented with $10 \%$ heat-inactivated fetal calf serum (FCS) Supernatants from the N2a cell culture medium were collected at $1 \mathrm{~h}, 2 \mathrm{~h}, 4 \mathrm{~h}, 12 \mathrm{~h}, 24 \mathrm{~h}, 2 \mathrm{~d}$ and $4 \mathrm{~d}$ after RSV infection and then 10 -fold serially diluted. Five hundred microliters of each diluted supernatant was added to the corresponding well. The plates were then incubated for $2 \mathrm{~h}$ at $37{ }^{\circ} \mathrm{C}$ with gentle shaking every $15 \mathrm{~min}$. The medium was removed from the wells, and the primary overlay, consisting of $1 \%$ SeaKem agarose mixed with $2 \times$ DMEM (1:1) and 5\% FCS, was added. The cultures were then incubated at $37{ }^{\circ} \mathrm{C}$ in $5 \% \mathrm{CO}_{2}$ for the indicated times required for each assay. Next, $1 \mathrm{ml}$ of crystal violet solution was added to each well, and the plates were incubated at room temperature (RT) for $1 \mathrm{~h}$. Finally, the plates were washed with fresh tap water and air-dried, and the total plaques in each well were then counted.

The experimental groups of $\mathrm{N} 2 \mathrm{a}$ cells were infected with RSV Long strain for varying durations, and normal cells were used as the uninfected control group.

\section{Antibodies and reagents}

A goat polyclonal antibody against TLR4 (sc-16,240), a rabbit polyclonal IgG antibody (sc-28,999) against TLR3 (M-300), and a rabbit polyclonal IgG antibody (sc-30,004) against TLR7 (H-114) were purchased from Santa Cruz Biotechnology (TX, USA). A rabbit polyclonal antibody against C23 (ab22758), a mouse monoclonal antibody against F protein (RSV3216 (B016), ab24011), an antiNeuN antibody (EPR12763, neuronal marker, ab177487), a donkey anti-goat IgG heavy and light chain (H\&L) antibody (Alexa Fluor 555, ab150130) against TLR4, a goat antirabbit IgG H\&L antibody (Alexa Fluor 488, ab150077) against C23, and a goat anti-mouse IgG H\&L antibody
(Alexa Fluor 647, ab150115) against RSV F were purchased from Abcam (Cambridge, UK). The Annexin V-FITC apoptosis kit (BB-4101) was obtained from BestBio (Shanghai, China), and enzyme-linked immunosorbent assay (ELISA) kits for IL-6 and TNF- $\alpha$ were obtained from Hermes Criterion Biotechnology (Vancouver, Canada).

\section{Indirect immunofluorescence assay and laser confocal microscopy}

N2a cells were plated on poly-L-lysine-coated glass coverslips at a density of $5 \times 10^{5}$ cells/well and cultured for $24 \mathrm{~h}$ in 6-well cell culture plates (Corning Inc.). After RSV inoculation, the cells were fixed with $4 \%$ formaldehyde for $30 \mathrm{~min}$ at RT. The cells were permeabilized with $0.3 \%$ Triton X-100 for $20 \mathrm{~min}$, and non-specific binding sites were blocked by incubation with $10 \%$ bovine serum albumin (BSA) for $30 \mathrm{~min}$. The cells were then incubated with specific primary antibodies, including an anti-NeuN antibody, an anti-RSV F protein antibody (1:300), an antiTLR4 antibody (1:300), and an anti-C23 antibody (1:300), overnight at $4{ }^{\circ} \mathrm{C}$. After washing with PBS $(3 \times 5 \mathrm{~min})$, the corresponding secondary antibodies conjugated to Alexa Fluor 555 (1:300), Alexa Fluor 488 (1:300), or Alexa Fluor 647 (1:300) were applied at RT for $1 \mathrm{~h}$. The cells were then stained with DAPI (1:1000, Beyotime, China) at RT for $10 \mathrm{~min}$, followed by mounting and examination with a laser scanning confocal microscope (SP8-DM26000, Leica, Germany).

\section{Co-immunoprecipitation assay}

Co-immunoprecipitation was performed using an immunoprecipitation kit (Thermo Scientific ${ }^{\mathrm{TM}}$ Pierce $^{\mathrm{TM}}$ CoImmunoprecipitation, Thermo Scientific Corp, USA) according to the manufacturer's instructions. Briefly, an anti-RSV F protein antibody was immobilized to the AminoLink coupling resin in a spin column, which was placed in a collection tube and centrifuged. The flowthrough was saved to verify antibody coupling. At $1 \mathrm{~h}$ post-infection (pi), $2 \mathrm{~h}$ pi, $4 \mathrm{~h}$ pi and $8 \mathrm{~h}$ pi, N2a cell lysates were prepared and centrifuged at $13,000 \times \mathrm{g}$ for $10 \mathrm{~min}$; the supernatants were then transferred to new tubes to determine the protein concentrations. The supernatants were pre-cleared with the corresponding control agarose resin before being applied to the immobilized antibody columns. The prey proteins were mixed with the resin and incubated by gentle mixing for $1-2 \mathrm{~h}$ or overnight at $4{ }^{\circ} \mathrm{C}$, followed by gentle washing with lysis buffer three times. Finally, the proteins were eluted with elution buffer and boiled for 5 min before being subjected to Western blot analysis. Polyvinylidene fluoride (PVDF) membranes were blocked with a solution containing primary antibodies against TLR4 and C23. A control lacking the primary antibodies was incubated with anti-mouse IgG. 


\section{Flow cytometry assay}

$\mathrm{N} 2$ a cell apoptosis was analyzed using an Annexin VFITC/PI apoptosis detection kit (BestBio, Shanghai, China) according to the manufacturer's instructions. Briefly, the cultures were washed twice with PBS and treated with EDTA-free trypsin for 5 min to dislodge the cells. Then, the cell suspensions were centrifuged at $300 \times \mathrm{g}$ for $5 \mathrm{~min}$ at $2-8{ }^{\circ} \mathrm{C}$. The pellets were resuspended in $400 \mu \mathrm{l}$ of Annexin V binding buffer, and the cell concentrations were adjusted to $1 \times 10^{6}$ cells $/ \mathrm{ml}$. After $10 \mu \mathrm{l}$ of Annexin V-FITC staining solution was added, the cells were incubated at $2-8{ }^{\circ} \mathrm{C}$ for $15 \mathrm{~min}$ in the dark. Then, $10 \mu \mathrm{l}$ of propidium iodide (PI) staining solution was added, and the cells were incubated in the dark for an additional $5 \mathrm{~min}$ at $2-8{ }^{\circ} \mathrm{C}$. When all the procedures were completed, the cells were immediately analyzed on a BD flow cytometer (BD FACS Calibur, BD Inc., USA).

\section{Co-localization analysis}

Co-localization is defined as an overlap in the physical distribution of two or more labeled structures within a 3-dimensional space. In the current study, colocalization of the RSV F protein with TLR4 and C23 was evaluated using an analytical tool from the LAS AF software package and analyzed using an intensity correlation coefficient-based method.

Regarding the correlation coefficients, intensity correlation coefficient-based co-localization analysis utilized a statistical method to evaluate the relationship between fluorescence intensities. A linear equation describing the relevance of the intensities in an image pair was calculated by linear regression. The slope of this linear approximation supplied the association rate of two fluorochromes, and the coefficient estimated the quality of the approximation. The experiments were run in triplicate.

\section{Western blot analysis}

N2a cells were harvested for Western blot analysis at different time points after RSV infection, and uninfected normal cells served as the control group. Briefly, cells were washed with PBS and lysed in lysis buffer containing phenylmethylsulfonyl fluoride (PMSF). The mixtures were kept on ice for $30 \mathrm{~min}$ and then centrifuged at 13,400 $\mathrm{xg}$ for $5 \mathrm{~min}$. The supernatants were collected and subjected to TLR4, C23, TLR3 and TLR7 protein detection. Equal amounts of total protein from each sample were loaded, separated by $10 \%$ SDS-PAGE, and then transferred to 0.45- $\mu$ m PVDF membranes (sc-296,042, Santa Cruz Biotechnology). The membranes were then blocked with PBS/0.1\% Tween-20 containing 5\% non-fat milk for $2 \mathrm{~h}$ at RT and probed with primary antibodies (1:500 dilution for the TLR4, C23 and TLR7 antibodies, 1:1000 dilution for the TLR3 antibody) at $4{ }^{\circ} \mathrm{C}$ overnight. The membranes were then incubated with horseradish peroxidaseconjugated anti-rabbit or anti-mouse secondary antibodies (1:10,000, Santa Cruz Biotechnology) for 2 h. Enhanced chemiluminescence (SuperSignal West Femto Substrate Kit, Thermo Scientific) was employed to develop the blots. Bands were detected using a Tanon 4500 automatic digital gel image analysis system (Tanon 4500, Shanghai, China). The relative intensity of each protein was normalized to that of $\beta$-actin and quantified using ImageJ software. Additionally, a $\beta$-actin monoclonal antibody (TA-09, ZSJG$\mathrm{BIO}$, Beijing, China) was used as the internal control.

\section{ELISA analysis}

The concentrations of IL- 6 and TNF- $\alpha$ in the culture supernatants were measured using commercial ELISA kits according to the manufacturer's instructions.

\section{Statistical analysis}

Data are presented as the mean \pm SEM. One-way analysis of variance (ANOVA) followed by Fisher's post hoc test were used to determine statistically significant differences between groups (SPSS 17.0, SPSS, Chicago, IL, USA). $p<$ 0.05 was considered significant, and $p<0.01$ was considered highly significant.

\section{Results \\ Altered NeuN protein expression and nuclear lesions in RSV-infected N2a cells}

$\mathrm{NeuN}$ is a neuronal nuclear protein marker associated with cell death [31]. As shown in Fig. 1, uniform distribution and abundance of the NeuN protein was observed in intact, highly dense cells of the uninfected control group. However, in RSV-infected N2a cells, the number of NeuN-positive cells was decreased at $24 \mathrm{~h}$ pi and $48 \mathrm{~h} \mathrm{pi}$, with nucleus shriveling and cell death being observed.

Additionally, changes in the nucleic morphologies of $\mathrm{N} 2 \mathrm{a}$ cells between pre- and post-RSV infection were examined by laser confocal microscopy. Nucleic cell lesions were not apparent during the early infection period but became much more apparent during late infection. As shown in Fig. 2a, nuclei of RSV-infected N2a cells became irregular, fragmented or incomplete with decreasing nuclear densities at $4 \mathrm{~d}$ pi compared to that in uninfected N2a cells. In addition, many N2a cells unadhered from the plate $4 \mathrm{~d}$ after RSV infection (Fig. 2b). To confirm these changes, RSV-permissive HEp-2 cells were also subjected to testing using the same experimental procedure, and similar results were observed (Fig. 2c and d), demonstrating that RSV Long strain prolifically infects $\mathrm{N} 2 \mathrm{a}$ cells and induces their death. 

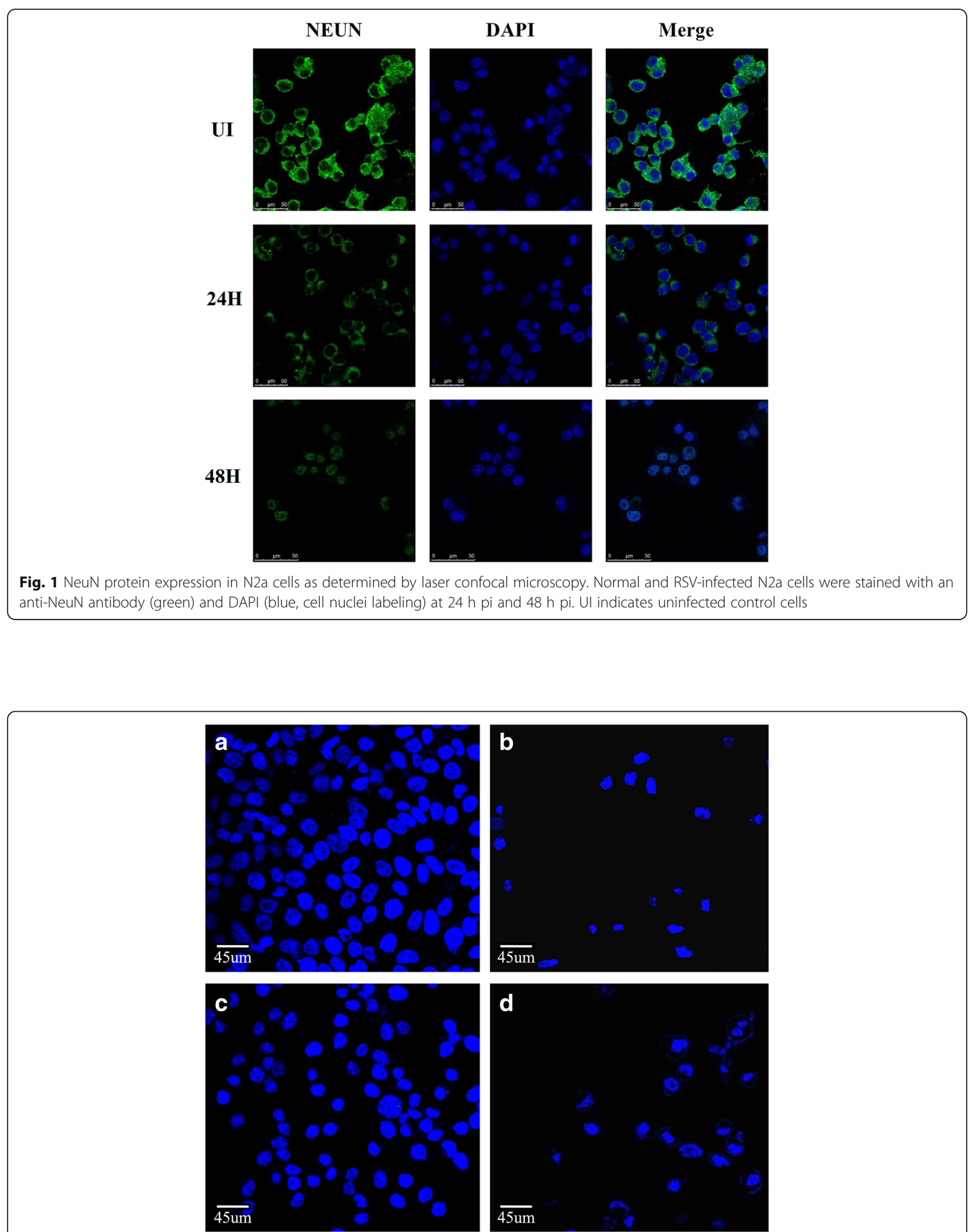

Fig. 2 Nucleic changes in N2a and HEp-2 cells were observed by laser confocal microscopy using DAPI staining. a Nuclei of normal N2a cells; b nuclei of RSV-infected N2a cells at 4 d pi; c nuclei of normal HEp-2 cells; d nuclei of RSV-infected HEp-2 cells at 16 h pi 
Increased RSV F protein expression in RSV-infected N2a cells As an RSV virion surface protein, $F$ protein plays an important role in RSV fusion and entry and is also required for RSV propagation in vivo and in vitro. In the current study, RSV-infected N2a cells were assayed by immunofluorescence at different time points pi to detect $\mathrm{F}$ protein expression. $\mathrm{F}$ protein expression increased as the duration of infection extended (Fig. 3), suggesting that RSV can multiply in these neuronal cells.

Increased viral titers in the culture supernatants of RSVinfected N2a cells

In this experiment, N2a cells were inoculated with RSV at an MOI of 2 and cultured for $1 \mathrm{~h}, 2 \mathrm{~h}, 4 \mathrm{~h}, 12 \mathrm{~h}, 24 \mathrm{~h}$, $2 \mathrm{~d}$ and $4 \mathrm{~d}$. At the indicated time points, the viral titers in N2a cell culture supernatants were determined by a plaque assay [30]. Figure 4 shows the upward trend in the mean values of RSV plaque-forming units (PFUs) in the supernatants, demonstrating that RSV replicated in $\mathrm{N} 2 \mathrm{a}$ cells in a time-dependent manner. Furthermore, replication was substantially more efficient between the $24 \mathrm{~h}$ and $4 \mathrm{~d}$ time points.

\section{Co-localization of the RSV F protein with TLR4 and C23}

The membrane receptors TLR4 and C23 reportedly recognize the RSV F protein. To further understand its function and reveal early molecular events induced by viral infection, co-localization of the RSV F protein with both TLR4 and C23 were investigated using confocal microscopy.

After inoculation with RSV, N2a cells were stained with fluorescence-labeled antibodies against the RSV $\mathrm{F}$ protein (cyan), TLR4 (red) and C23 (green) at $1 \mathrm{~h}$, $2 \mathrm{~h}$ and $4 \mathrm{~h}$ pi. F protein expression and RSV proliferation in N2a cells increased in a time-dependent manner (Fig. 5a). As shown in Fig. 5b, the RSV F protein both co-localized and exhibited a correlative intensity with TLR4 and C23. These results were consistent with the findings of Tayyari et al. that C23 is recognized by the RSV F protein [21] and Rallabhandi et al. that the TLR4 signaling pathway is activated by the RSV F protein [27].

Potential interactions of the RSV F protein with TLR4 and C23 detected by co-immunoprecipitation

Immunoprecipitants containing prey proteins (TLR4 and $\mathrm{C} 23$ ), which potentially interact with the F protein, were pulled down using an anti-F protein antibody and then subjected to Western blot analysis. As shown in Fig. 6, TLR4 and C23 immunoprecipitation was significantly increased from $1 \mathrm{~h}$ pi to $4 \mathrm{~h}$ pi but decreased thereafter. A similar immunoprecipitation phenomenon was observed with $\mathrm{C} 23$. In the negative control group, lacking primary antibodies against TLR4 and C23, no bands were detected by the co-immunoprecipitation assay using anti-mouse IgG.

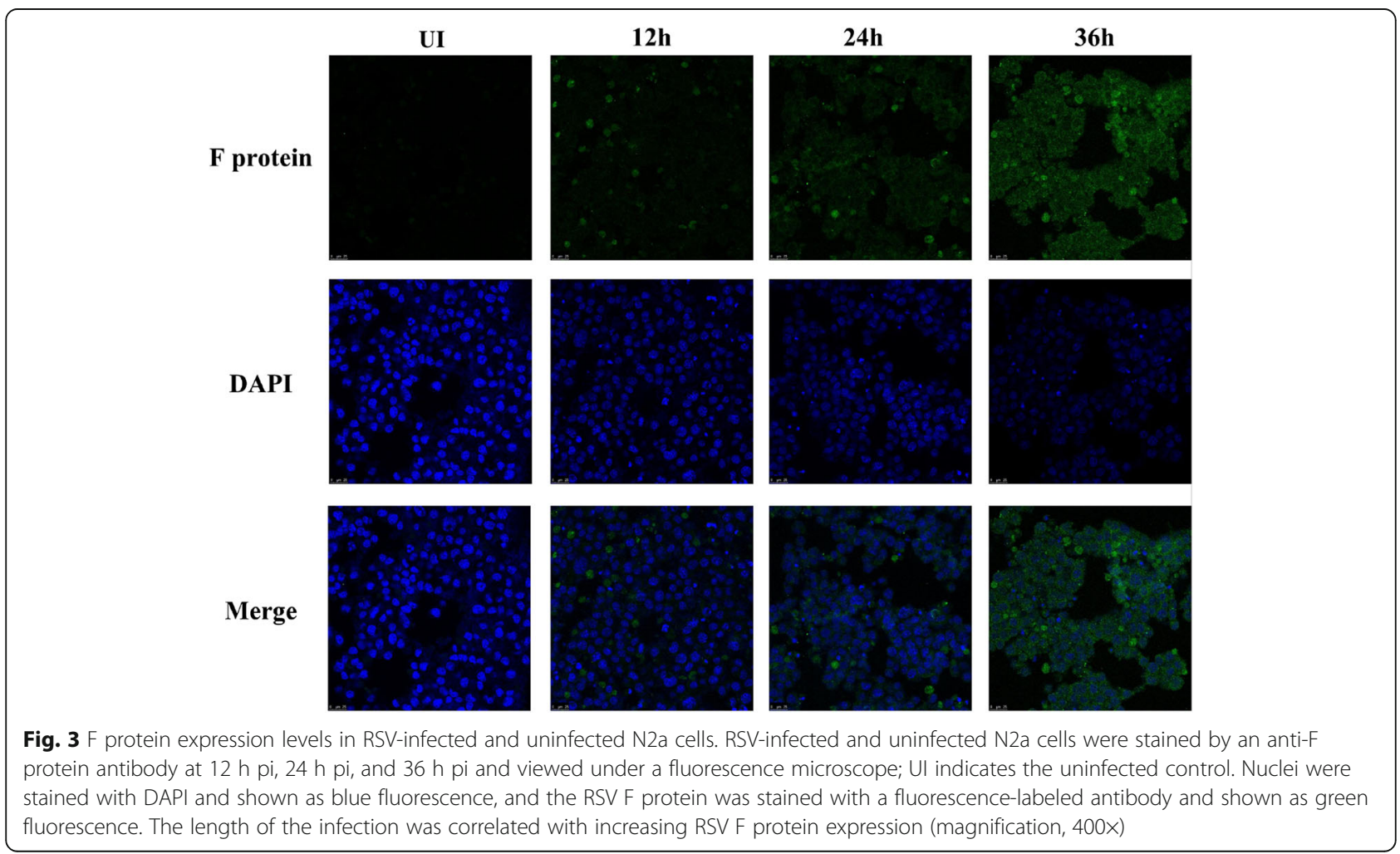




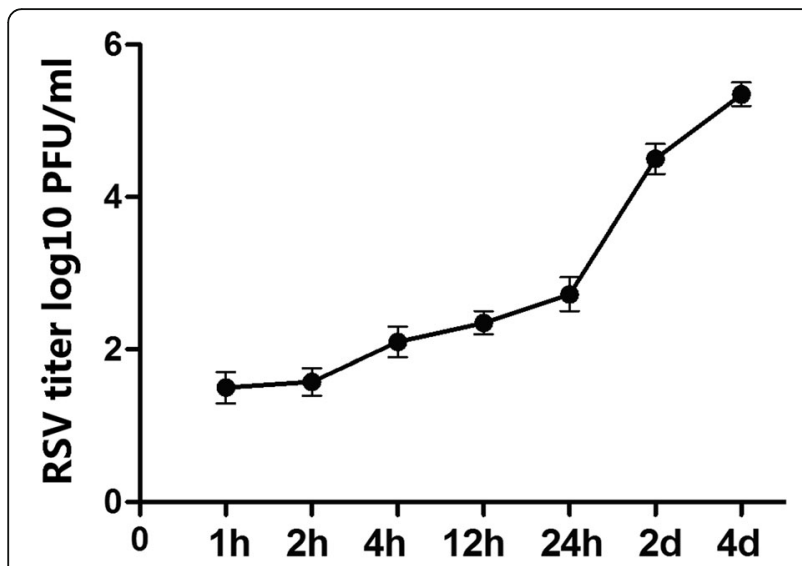

Fig. 4 RSV viral titers in the culture supernatants of RSV-infected and uninfected N2a cells. Supernatants from each group of cells were collected at 1 h pi, 2 h pi, 4 h pi, 12 h pi, 24 h pi, 2 d pi, and $4 \mathrm{~d} \mathrm{pi}$ to determine the viral titers (PFU) using the RSV plaque assay. Their numeric units are represented as log $10 \mathrm{PFU} / \mathrm{ml}$. Data are expressed as the mean $\pm \mathrm{SEM}$, and all tests were run in triplicate

\section{Altered TLR4 and C23 protein expression levels in RSV- infected N2a cells}

TLR4 and C23 expression was examined by Western blot analysis at the indicated time points pi (Fig. 7). In the RSV-infected group, expression of the TLR4 protein was very low at $0 \mathrm{~h} \mathrm{pi}$, significantly increased from $1 \mathrm{~h}$ pi to $4 \mathrm{~h}$ pi, $(P<0.01)$, and decreased from $12 \mathrm{~h}$ pi to 4 $\mathrm{d}$ pi. Although a decrease in expression was observed, the expression level of TLR4 from $12 \mathrm{~h}$ pi to $2 \mathrm{~d}$ pi in the RSV-infected group remained higher than that in the uninfected control group $(P<0.01)$. However, the differences were not significant at the $4 \mathrm{~d}$ pi time point.

The variation tendencies of $\mathrm{C} 23$ protein expression were similar to those of TLR4. The difference in C23 expression between the RSV-infected group and the uninfected control group was statistically significant prior to $2 \mathrm{~d}$ pi $(P<0.01$ and $P<0.05$, respectively) but became statistically insignificant at the $4 \mathrm{~d}$ pi time point.

\section{Changes in the apoptosis of RSV-infected N2a neuronal cells}

To investigate changes in the apoptosis levels of both RSV-infected N2a cells and uninfected control cells, flow cytometry analysis was adopted using FITCconjugated Annexin V and PI staining. As shown in Fig. 8, no early or late apoptotic cells were detected at $0 \mathrm{~h} \mathrm{pi}, 1 \mathrm{~h}$ pi, $2 \mathrm{~h}$ pi, $4 \mathrm{~h}$ pi, $12 \mathrm{~h}$ pi or $24 \mathrm{~h}$ pi (Fig. 8a-f). At $2 \mathrm{~d}$ pi, the proportion of early apoptotic cells (Annexin $\mathrm{V}^{+}, \mathrm{PI}^{-}$) reached $32.89 \%$ in $\mathrm{N} 2 \mathrm{a}$ cells, which was statistically significant, while the proportion of late apoptotic cells (Annexin $\mathrm{V}^{+}, \mathrm{PI}^{+}$) was $8.75 \%$, statistically insignificant. At $3 \mathrm{~d}$ and $4 \mathrm{~d}$ pi, the early apoptosis ratios reached 26.01 and 14.69\%, and the late apoptosis ratios reached 19.34 and $31.57 \%$, respectively (Fig. $8 g-i$ ), both of which were statistically significant different compared with those in the uninfected control group. Additionally, necrosis and apoptosis were not apparent in the uninfected control group at $2 \mathrm{~d}$ pi, $3 \mathrm{~d}$ pi or $4 \mathrm{~d}$ pi (Fig. $8 \mathrm{j}-\mathrm{l}$ ) Therefore, from $2 \mathrm{~d}$ pi to $4 \mathrm{~d}$ pi, longer durations of RSV infection appeared to correlate with a gradual decrease in early apoptotic cells and a gradual increase in late apoptotic cells.

\section{Increased TLR3 and TLR7 expression in RSV-infected N2a cells}

To further evaluate the activating effects of RSV infection on intracellular TLRs, the protein expression levels of TLR3 and TLR7 in both the RSV-infected group and the uninfected control group were analyzed by Western blot. TLR3 protein expression in the RSV-infected group steadily increased from the starting time at $1 \mathrm{~h}$ pi (Fig. 9a) in a time-dependent manner compared with that in the uninfected control group $(P<0.01)$. Similarly, expression of the TLR7 protein was relatively low in the uninfected control group, and TLR7 protein expression in the RSVinfected group increased as the duration of RSV infection extended in a time-dependent manner. (Fig. 9b). This increase in the RSV-infected group was significantly different from that in the uninfected control group $(P<0.05)$.

\section{Increased IL-6 and TNF-a levels in the culture supernatants of RSV-infected N2a cells}

RSV-induced encephalopathy is accompanied by neuronal cell damage and frequently altered expression levels of pro-inflammatory cytokines, such as IL-6, IL-8 and TNF$\alpha$. Therefore, variations in pro-inflammatory cytokine levels in the culture supernatants of virus-infected N2a cells potentially confirm the proliferation of viral infection in N2a neuronal cells. Thus, the protein expression levels of IL- 6 and TNF- $\alpha$ in RSV-infected N2a neuronal cells were assessed by ELISA. IL- 6 and TNF- $\alpha$ levels in the RSV-infected group were substantially elevated compared with that in the uninfected control group as the duration of RSV infection extended $(P<0.01)$, suggesting that encephalopathy-associated pro-inflammatory molecules are induced by RSV infection in N2a cells (Fig. 10).

\section{Discussion}

RSV is the major pathogen responsible for acute lower respiratory infections in human infants [32], and Zlateva et al. suggested that RSV might cause neurological complications in infants [5]. In addition, some cases of RSV being potentially associated with clinical encephalopathy, coughing and runny nose symptoms in RSV-infected children who developed unconsciousness and hypotonia have been reported [33]. Furthermore, the RSV viral 

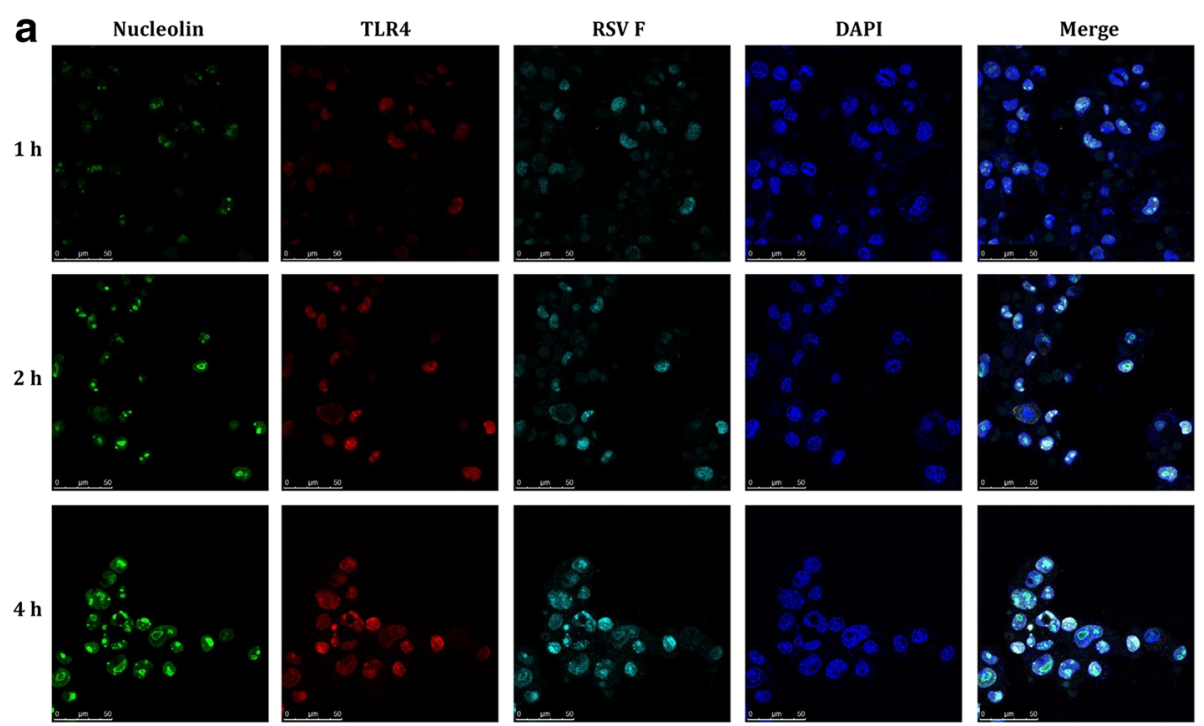

b
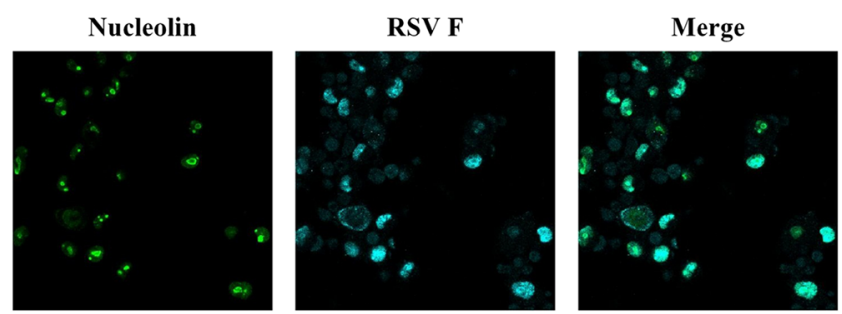

TLR4

RSV F
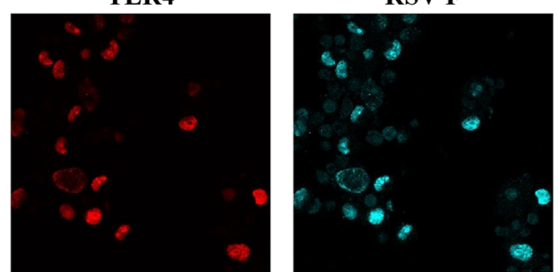

Merge

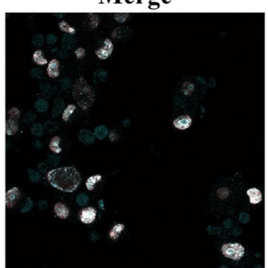

Fig. 5 Co-localization of the RSV F protein with the cell surface receptors TLR4 and nucleolin and internalization of the RSV F protein into N2a cells were examined by laser confocal microscopy. N2a cells were fixed and stained with fluorescence-labeled antibodies against TLR4 (red), nucleolin (green) and the RSV F protein (cyan) at different time points after RSV infection. Simultaneously, N2a cell nuclei were counterstained with DAPI. a The RSV F protein co-localized with both TLR4 and nucleolin at $1 \mathrm{~h} \mathrm{pi,} 2 \mathrm{~h}$ pi and $4 \mathrm{~h}$ pi; $\mathbf{b}$ The RSV F protein co-localized with TLR4 and nucleolin in N2a cells at $2 \mathrm{~h}$ pi; nucleolin is labeled with Alexa 488 (green fluorescence), TLR4 is labeled with Alexa 555 (red fluorescence), and $\mathrm{F}$ protein is labeled with Alexa 647 (cyan fluorescence). Co-localization was evaluated using an analytic tool from the LAS AF

software package

genome has been detected in the cerebrospinal fluid of children infected with RSV diseases [5, 34]. Because virus-induced encephalopathy may lead to sudden infant death syndrome [2, 3], determining whether RSV can infect neuronal cells or access children brains via the CNS is very important. Based on the report that coronaviruses (CoVs) may access the CNS by crossing the blood brain barrier (BBB) [35], herein, neuronal N2a cells were selected to test whether RSV can infect the CNS and induce neuronal damage.

Though many clinical cases of RSV-induced encephalopathy have been reported, relative experimental research was unfortunately seldom conducted, and the mechanisms underlying this disease have yet to be elucidated. Thus far, no effective treatments have been identified, and basic studies reporting virus-induced encephalopathy have been limited to the rabies and influenza viruses [10,36]. Thus, in the current study, the pathogenesis of RSV-associated encephalopathy was preliminarily explored. Specifically, the roles of two membrane receptors, TLR4 and C23, in the process of RSV infecting neuronal cells were investigated.

First, the infectivity of RSV in N2a neuronal cells was assessed. As shown in Figs. 1 and 2, the number of NeuN-positive cells decreased, and their cellular and nuclear morphological characteristics were altered at $4 \mathrm{~d}$ after RSV infection, as determined by light and confocal 


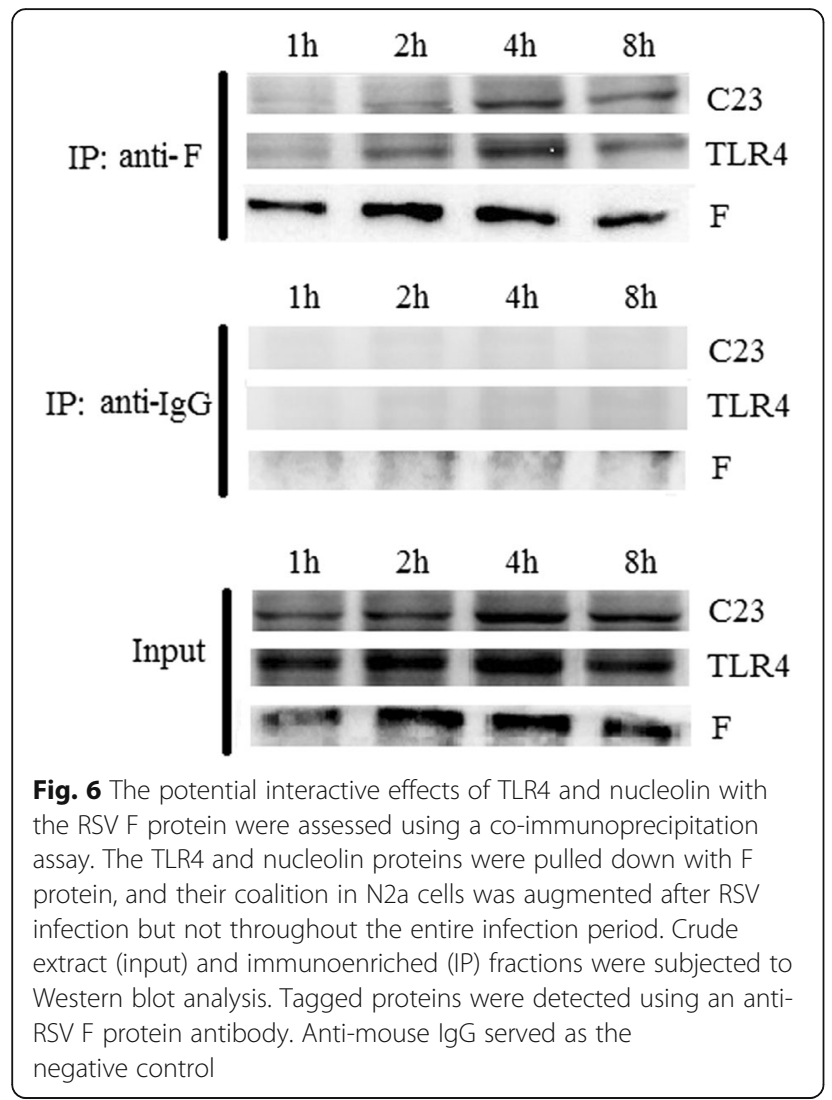

microscopy. Additionally, expression of the RSV F protein in virus-infected $\mathrm{N} 2 \mathrm{a}$ cells increased in a timedependent manner (Fig. 3). These data confirmed that RSV can infect, propagate and proliferate in N2a cells.

Second, the co-localization and potential interactions of the RSV F protein with TLR4 and C23 were investigated by laser confocal microscopy and a coimmunoprecipitation assay. The $\mathrm{F}$ protein was found to co-localize with both the TLR4 and C23 receptors at $1 \mathrm{~h}$ pi (Figs. 5 and 6). The baseline level of C23 expression was slightly higher than that of TLR4, but both TLR4 and $\mathrm{C} 23$ protein expression were up-regulated from $1 \mathrm{~h}$ pi to $4 \mathrm{~h} \mathrm{pi,} \mathrm{which} \mathrm{is} \mathrm{during} \mathrm{the} \mathrm{early} \mathrm{stage} \mathrm{of} \mathrm{infection}$ (Fig. 7). Interestingly, both TLR4 and C23 protein levels were down-regulated beginning $4 \mathrm{~h}$ pi (late stage of infection), suggesting that these two receptors may participate in the early recognition and modulation of viral entry into N2a cells. We also speculated that TLR4 and C23 have no additional functions after RSV is internalized, as the expression levels of these two membrane receptors were decreased after $4 \mathrm{~h}$ of infection. These data are consistent with those of the laser confocal microscopy and co-immunoprecipitation experiments. TLR4 expression in neurons of traumatic encephalopathy patients has also been reported to increase at early infection and decrease at late infection, and TLR4 is thought to play a vital role in inflammatory responses involving MyD88/NF- $\mathrm{kB}$ activation and initiate the TLR4/MyD88/NF- $\mathrm{BB}$ signaling pathway [26,37], suggesting that TLR4 is very important for the ability of RSV to infect neuronal cells.

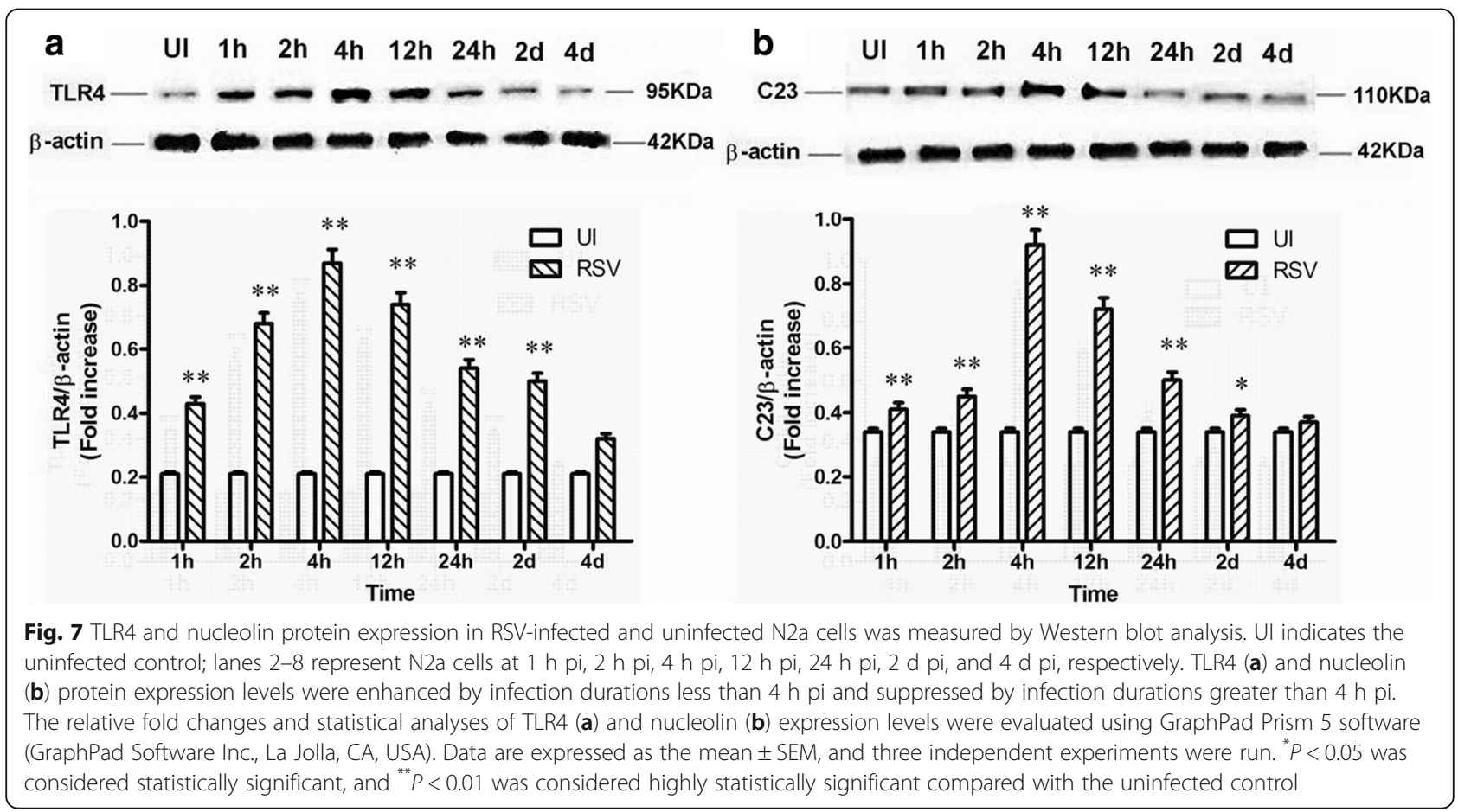



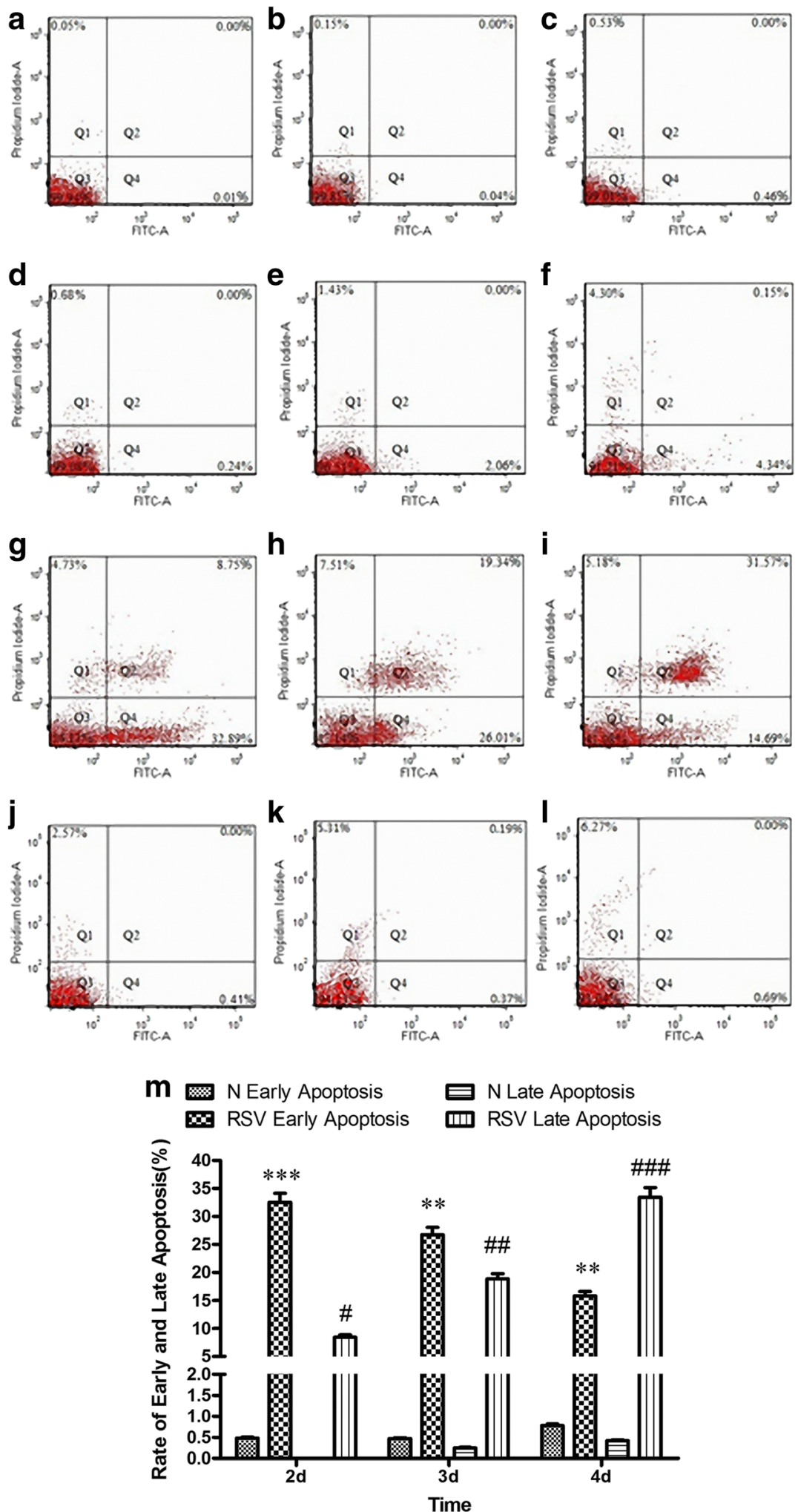

(m)

Fig. 8 (See legend on next page.) 
(See figure on previous page.)

Fig. 8 Apoptosis analysis of RSV-infected N2a neuronal cells. After RSV infection, N2a cells were stained with FITC, Annexin-V and PI and subjected to flow cytometry analysis. Panels $\mathbf{a}, \mathbf{b}, \mathbf{c}, \mathbf{d}, \mathbf{e}, \mathbf{f}, \mathbf{g}, \mathbf{h}$, and $\mathbf{i}$ represent the apoptotic statuses of N2a cells at 0 h, 1 h, 2 h, 4 h, 12 h, 24 h, $2 \mathrm{~d}, 3 \mathrm{~d}$ and $4 \mathrm{~d}$ after RSV infection, respectively. Panels $\mathbf{j}, \mathbf{k}$, and I represent the apoptotic statuses of uninfected N2a cells at $2 \mathrm{~d}, 3 \mathrm{~d}$ and $4 \mathrm{~d}$, respectively. Data are expressed as the mean \pm SEM, and all tests were run in triplicate (shown in fig. $\mathrm{m}$ ). ${ }^{*} P<0.05,{ }^{* * *} P<0.01$, and ${ }^{* * *} P<0.001$ indicate the

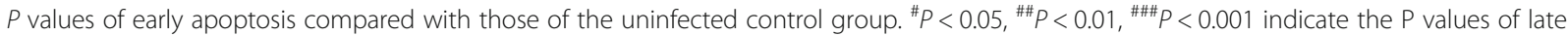
apoptosis compared with those of the uninfected control group

Third, because apoptosis may involve virus-cell interactions and induce cellular damage during the viral infection process, the apoptosis rates of N2a cells after RSV infection were measured in this study. Early apoptosis occurred at $2 \mathrm{~d}$ pi, and late apoptosis occurred as the duration of RSV infection extended. These findings demonstrated the presence of apoptotic lesions during the RSV infection process.

Fourth, because TLRs are expressed in both nonneuronal and neuronal cell types in the CNS and contribute to both infectious and non-infectious disorders [38], TLR3 and TLR7 are thought to be major mediators of virus-induced signaling pathways during RSV infection [39, 40]. TLR3 activation is associated with neuroinflammation and common CNS disease pathologies [41], and TLR7 is up-regulated upon chikungunya virus (CHIKV) infection and plays an important role in CHIKV pathogenesis in neuronal cells [42]. Moreover, TLR activation in dendritic and neuronal cells has been reported to drive a protective antiviral response [43, 44]. Thus, in this study, variations in TLR3 and TLR7 expression in RSVinfected N2a cells were determined. Both TLR3 and TLR7 protein levels continuously increased as the duration of RSV infection was extended, confirming the role of TLR-mediated innate immune responses in RSV pathogenesis.

The experiments of this study were performed in triplicate, and consistent results were achieved. However, our study does have some limitations. For example, regarding the receptor-mediated effects on virus invasion, only preliminary evidence was obtained. Regarding the roles of TLR4 and C23 in RSV-infected neurons, the RSV F protein was shown to co-localize with both TLR4 and $\mathrm{C} 23$, but their specific interactions and binding were not fully investigated. Further experiments, such as yeast two hybrid, GST pull-down and RNA interference experiments, are required to confirm the interactive activity of the RSV F protein with TLR4 and C23.

Based on the above experiments, RSV Long strain prolifically infects $\mathrm{N} 2 \mathrm{a}$ neuronal cells and induces cell lesions, and TLR4 and C23 expressed on the cell membrane surface might mediate the viral entry process in N2a cells and further activate expression of the intracellular receptors TLR3 and TLR7. Simultaneously, TLR-associated downstream inflammatory factors, such as IL- 6 and TNF- $\alpha$, are released from N2a cells by RSV invasion. Notably, the results obtained herein from
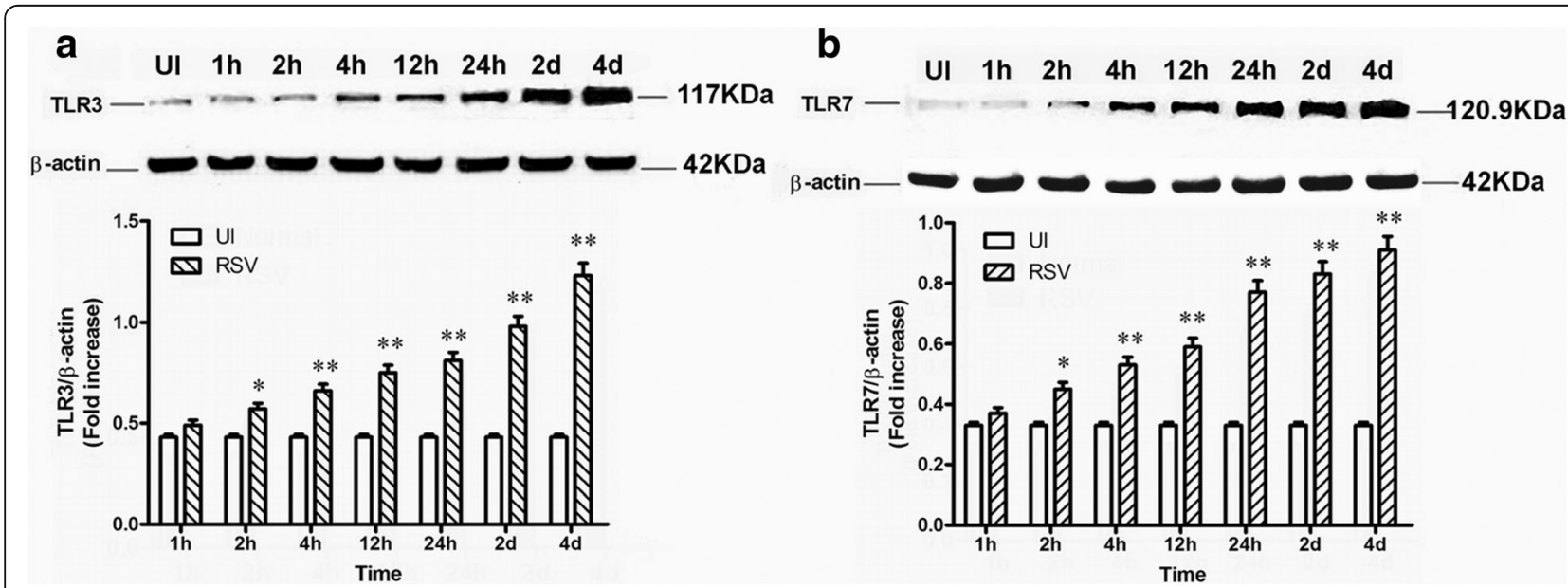

Fig. 9 TLR3 and TLR7 protein expression in RSV-infected and uninfected N2a cells at different time points as determined by Western blot analysis. Lane 1: mock control; lanes 2-8: RSV-infected N2a cells at the time points $1 \mathrm{~h}$ pi, 2 h pi, 4 h pi, 12 h pi, 24 h pi, $2 \mathrm{~d}$ pi, and $4 \mathrm{~d}$ pi, respectively. The protein levels of TLR3 (a) and TLR7 (b) were enhanced as the duration of RSV infection was extended. In addition, the statistical significance of relative fold changes in TLR3 (a) and TLR7 (b) expression were evaluated using GraphPad Prism 5 software (GraphPad Software Inc.). Data are expressed as the mean \pm SEM, and three independent experiments were run. ${ }^{*} P<0.05$, was considered statistically significant, and ${ }^{* *} P<0.01$ was considered highly statistically significant compared with the uninfected control 

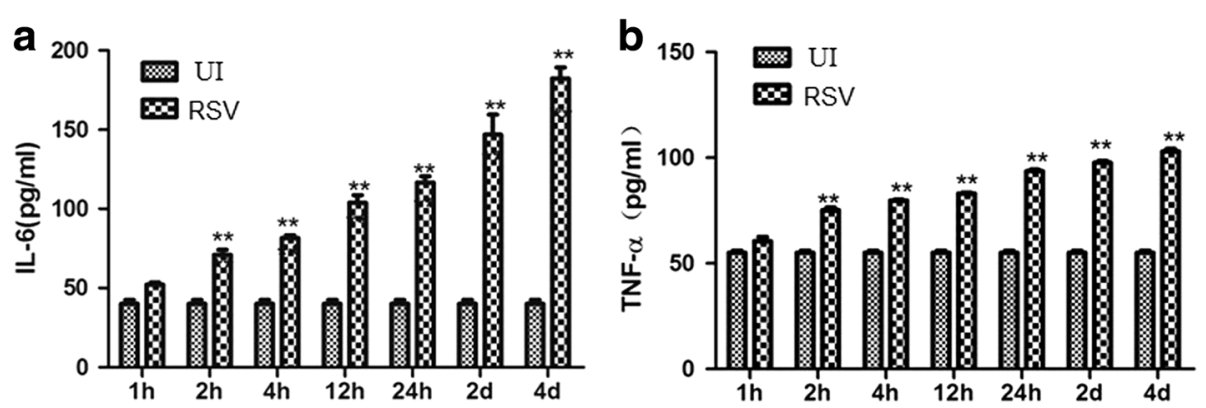

Fig. 10 Expression levels of inflammatory cytokines in the culture supernatants of RSV-infected and uninfected N2a cells as measured by ELISA. The expression levels of IL-6 (a) and TNF-a (b) were enhanced as the duration of RSV infection was extended. UI indicates the uninfected control. Data are expressed as the mean \pm SEM, and three independent experiments were run. ${ }^{*} P<0.05$ was considered statistically significant, and ${ }^{* *} P<0.01$ was considered highly statistically significant compared with the uninfected control

RSV-infected N2a cells are similar to those obtained from CHIKV virus-infected N2a cells [42].

\section{Conclusions}

In summary, our data demonstrated that RSV prolifically entered and infected N2a neuronal cells, leading to the modulated expression of TLR4 and C23 as well as of TLR3, TLR7 and their downstream inflammatory factors, suggesting a direct induction of RSV-associated encephalopathy in infants by the RSV infection of neuronal cells. During these processes, the RSV F protein colocalized with TLR4 and C23 and thus may play an essential role in the RSV infection of N2a cells. Taken together, the results presented here may help elucidate the underlying pathology of RSV infection and suggest potential therapeutic targets for the control and prevention of RSV-induced human diseases.

\section{Abbreviations \\ C23: Nucleolin; CNS: Central nervous system; CoVs: Coronaviruses; CSF: Cerebrospinal fluid; FCS: Fetal calf serum; JEV: Japanese encephalitis virus; LPS: Lipopolysaccharides; MOI: Multiplicity of infection; N2a: Neuro-2a; PFUs: Plaque-forming units; pi: Post-infection; PI: Propidium iodide; PMSF: Phenylmethylsulfonyl fluoride; PVDF: Polyvinylidene fluoride; RSV: Respiratory syncytial virus; RT: Room temperature; SDS-PAGE: Sodium dodecyl sulfate-polyacrylamide gel electrophoresis; TLR4: Toll-like receptor 4; TLRs: Toll-like receptors}

\section{Acknowledgments}

We are grateful to Prof. Yu-Xian Shen (Anhui Medical University, Hefei, China) for kindly providing the N2a cells.

\section{Funding}

This work was supported by grants from the Natural Science Foundation of China (grant no. 81371797), the Natural Science Research of Anhui Education Department key projects (grant no. KJ2016A248 and KJ2012A152) and the Provincial Quality project of China (grant no. 201610366067).

Availability of data and materials Not applicable.

\section{Authors' contributions}

$\mathrm{SHH}$ conceived, designed, and coordinated this study and helped revise the manuscript. XLY participated in the study design and drafted the manuscript. TH drafted the manuscript. HWH performed the statistical analysis. HQ performed the laser confocal microscopy assay. XW carried out the immunoblotting assay. CC prepared the figures and illustrations. MMW analyzed the data and interpreted the experimental results. JXC edited and revised the manuscript. All authors read and approved the final version of the manuscript.

Ethics approval and consent to participate Not applicable.

\section{Consent for publication}

We accept the conditions of submission and the BioMed Central Copyright and License Agreement. All authors approve the manuscript submitted for publication.

\section{Competing interests}

The authors declare that they have no competing interests.

\section{Publisher's Note}

Springer Nature remains neutral with regard to jurisdictional claims in published maps and institutional affiliations.

\section{Author details}

${ }^{1}$ Department of Microbiology, School of Basic Medicine, Anhui Medical University, Hefei, Anhui Province 230032, People's Republic of China. ${ }^{2}$ School of Life Sciences, Anhui Medical University, Hefei, Anhui Province 230032, People's Republic of China. ${ }^{3}$ Department of Laboratory Medicine, Anhui Health College, Chizhou, Anhui Province 247099, People's Republic of China. ${ }^{4}$ Department of Pathology and Cell Biology, Columbia University, New York, NY 10032, USA. ${ }^{5}$ Department of Clinical Medicine, Anhui Medical University, Hefei, Anhui Province 230032, People's Republic of China.

Received: 9 November 2017 Accepted: 2 February 2018

Published online: 10 February 2018

\section{References}

1. Rima B, Collins P, Easton A, Fouchier R, Kurath G, Lamb RA, et al. ICTV virus taxonomy profile: Pneumoviridae. J Gen Virol. 2017;98:2912-3.

2. Morichi S, Kawashima H, loi H, Ushio M, Yamanaka G, Kashiwagi Y, et al. Cerebrospinal fluid NOx (nitrite/nitrate) in RSV-infected children with CNS symptoms. J Inf Secur. 2009:59:299-301.

3. Morichi S, Kawashima H, loi H, Yamanaka G, Kashiwagi Y, Hoshika A, et al. Classification of acute encephalopathy in respiratory syncytial virus infection. J Infect Chemother. 2011;17:776-81.

4. Nakamura K, Kato M, Sasaki A, Shiihara T, Hayasaka K. Respiratory syncytial virus-associated encephalopathy complicated by congenital myopathy. Pediatr Int. 2012;54:709-11.

5. Zlateva KT, Van Ranst M. Detection of subgroup B respiratory syncytial virus in the cerebrospinal fluid of a patient with respiratory syncytial virus pneumonia. Pediatr Infect Dis J. 2004;23:1065-6.

6. Thongtan T, Wikan N, Wintachai P, Rattanarungsan C, Srisomsap C, Cheepsunthorn P, et al. Characterization of putative Japanese encephalitis virus receptor molecules on microglial cells. J Med Virol. 2012;84:615-23. 
7. LePage KT, Dickey RW, Gerwick WH, Jester EL, Murray TF. On the use of neuro-2a neuroblastoma cells versus intact neurons in primary culture for neurotoxicity studies. Crit Rev Neurobiol. 2005;17:27-50.

8. Provost P. Interpretation and applicability of microRNA data to the context of Alzheimer's and age-related diseases. Aging. 2010;2:166-9.

9. Chen F, Palem J, Balish M, Figliozzi R, Ajavon A, Hsia SV. A novel thyroid hormone mediated regulation of HSV-1 gene expression and replication is specific to neuronal cells and associated with disruption of chromatin condensation. SOJ Pharm Pharm Sci. 2014;1

10. Wang X, Zhang S, Sun C, Yuan ZG, Wu X, Wang D, Ding Z, Hu R. Proteomic profiles of mouse neuro N2a cells infected with variant virulence of rabies viruses. J Microbiol Biotechnol. 2011;21:366-73.

11. Gupta N, Santhosh SR, Babu JP, Parida MM, Rao PV. Chemokine profiling of Japanese encephalitis virus-infected mouse neuroblastoma cells by microarray and real-time RT-PCR: implication in neuropathogenesis. Virus Res. 2010;147:107-12.

12. Take M, Tsutsui J, Obama H, Ozawa M, Nakayama T, Maruyama I, et al, Identification of nucleolin as a binding protein for midkine (MK) and heparin-binding growth associated molecule (HB-GAM). J Biochem. 1994; 116:1063-8

13. Said EA, Krust B, Nisole S, Svab J, Briand JP, Hovanessian AG. The anti-HIV cytokine midkine binds the cell surface-expressed nucleolin as a low affinity receptor. J Biol Chem. 2002;277:37492-502.

14. Larrucea S, Gonzalez-Rubio C, Cambronero R, Ballou B, Bonay P, Lopez-

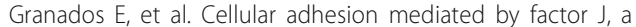
complement inhibitor. Evidence for nucleolin involvement. J Biol Chem. 1998;273:31718-25.

15. Semenkovich CF, Ostlund RE Jr, Olson MO, Yang JW. A protein partially expressed on the surface of HepG2 cells that binds lipoproteins specifically is nucleolin. Biochemistry. 1990;29:9708-13.

16. Srivastava M, Pollard HB. Molecular dissection of nucleolin's role in growth and cell proliferation: new insights. FASEB J. 1999:13:1911-22.

17. Wang Y, Mao M, Xu JC. Cell-surface nucleolin is involved in lipopolysaccharide internalization and signalling in alveolar macrophages. Cell Biol Int. 2011;35:677-85.

18. Nisole S, Krust B, Callebaut C, Guichard G, Muller S, Briand JP, et al. The antiHIV pseudopeptide HB-19 forms a complex with the cell-surface-expressed nucleolin independent of heparan sulfate proteoglycans. J Biol Chem. 1999; 274:27875-84.

19. Nisole S, Said EA, Mische C, Prevost MC, Krust B, Bouvet P, et al. The anti-HIV pentameric pseudopeptide HB-19 binds the C-terminal end of nucleolin and prevents anchorage of virus particles in the plasma membrane of target cells. J Biol Chem. 2002;277:20877-86.

20. Bugler B, Caizergues-Ferrer M, Bouche G, Bourbon H, Amalric F. Detection and localization of a class of proteins immunologically related to a $100-\mathrm{kDa}$ nucleolar protein. Eur J Biochem. 1982;128:475-80.

21. Tayyari F, Marchant D, Moraes TJ, Duan W, Mastrangelo P, Hegele RG Identification of nucleolin as a cellular receptor for human respiratory syncytial virus. Nat Med. 2011;17:1132-5.

22. Tufaro F. Virus entry: two receptors are better than one. Trends Microbiol. 1997:5:257-8. discussion 8-9

23. Leistner CM, Gruen-Bernhard S, Glebe D. Role of glycosaminoglycans for binding and infection of hepatitis B virus. Cell Microbiol. 2008:10:122-33.

24. Abdi J, Garssen J, Redegeld F. Toll-like receptors in human multiple myeloma: new insight into inflammation-related pathogenesis. Curr Mol Med. 2014;14:423-31.

25. Kurt-Jones EA, Popova L, Kwinn L, Haynes LM, Jones LP, Tripp RA, et al. Pattern recognition receptors TLR4 and CD14 mediate response to respiratory syncytial virus. Nat Immunol. 2000;1:398-401.

26. Marr N, Turvey SE. Role of human TLR4 in respiratory syncytial virus-induced NF-kappaB activation, viral entry and replication. Innate Immun. 2012:18:856-65.

27. Rallabhandi P, Phillips RL, Boukhvalova MS, Pletneva LM, Shirey KA, Gioannini TL, et al. Respiratory syncytial virus fusion protein-induced toll-like receptor 4 (TLR4) signaling is inhibited by the TLR4 antagonists Rhodobacter sphaeroides lipopolysaccharide and eritoran (E5564) and requires direct interaction with MD-2. MBio. 2012;3:e00218-12. https://doi. org/10.1128/mBio.00218-12.

28. Lehnardt S, Schott E, Trimbuch T, Laubisch D, Krueger C, Wulczyn G, et al. A vicious cycle involving release of heat shock protein 60 from injured cells and activation of toll-like receptor 4 mediates neurodegeneration in the CNS. J Neurosci. 2008;28:2320-31.
29. Caudle WM, Kitsou E, Li J, Bradner J, Zhang J. A role for a novel protein, nucleolin, in Parkinson's disease. Neurosci Lett. 2009:459:11-5.

30. Kisch AL, Johnson KM. A plaque assay for respiratory syncytial virus. Proc Soc Exp Biol Med. 1963;112:583-9.

31. Sarnat HB, Nochlin D, Born DE. Neuronal nuclear antigen (NeuN): a marker of neuronal maturation in early human fetal nervous system. Brain Dev. 1998;20:88-94

32. Sadreameli SC, Reller ME, Bundy DG, Casella JF, Strouse JJ. Respiratory syncytial virus and seasonal influenza cause similar illnesses in children with sickle cell disease. Pediatr Blood Cancer. 2014;61:875-8.

33. Miyamoto K, Fujisawa M, Hozumi H, Tsuboi T, Kuwashima S, Hirao J, et al. Systemic inflammatory response syndrome and prolonged hypoperfusion lesions in an infant with respiratory syncytial virus encephalopathy. J Infect Chemother. 2013;19:978-82.

34. Ichiyama T, Suenaga N, Kajimoto M, Tohyama J, Isumi H, Kubota M, et al. Serum and CSF levels of cytokines in acute encephalopathy following prolonged febrile seizures. Brain Dev. 2008:30:47-52.

35. Cabirac GF, Soike KF, Zhang JY, Hoel K, Butunoi C, Cai GY, et al. Entry of coronavirus into primate CNS following peripheral infection. Microb Pathog. 1994;16:349-57.

36. Jang H, Boltz D, Sturm-Ramirez K, Shepherd KR, Jiao Y, Webster R, et al. Highly pathogenic $\mathrm{H} 5 \mathrm{~N} 1$ influenza virus can enter the central nervous system and induce neuroinflammation and neurodegeneration. Proc Natl Acad Sci U S A. 2009;106:14063-8.

37. Zhu HT, Bian C, Yuan JC, Chu WH, Xiang X, Chen F, et al. Curcumin attenuates acute inflammatory injury by inhibiting the TLR4/MyD88/NFkappaB signaling pathway in experimental traumatic brain injury. J Neuroinflammation. 2014;11:59. https://doi.org/10.1186/1742-2094-11-59.

38. Liu T, Gao YJ, Ji RR. Emerging role of toll-like receptors in the control of pain and itch. Neurosci Bull. 2012;28:131-44.

39. Lehmann SM, Rosenberger K, Kruger C, Habbel P, Derkow K, Kaul D, et al. Extracellularly delivered single-stranded viral RNA causes neurodegeneration dependent on TLR7. J Immunol. 2012;189:1448-58.

40. Kumar H, Kawai T, Akira S. Pathogen recognition by the innate immune system. Int Rev Immunol. 2011;30:16-34.

41. Facci L, Barbierato M, Marinelli C, Argentini C, Skaper SD, Giusti P. Toll-like receptors $2,-3$ and -4 prime microglia but not astrocytes across central nervous system regions for ATP-dependent interleukin-1 beta release. Sci Rep. 2014;4:6824. https://doi.org/10.1038/srep06824.

42. Priya R, Dhanwani R, Patro IK, Rao PV, Parida MM. Differential regulation of TLR mediated innate immune response of mouse neuronal cells following infection with novel ECSA genotype of Chikungunya virus with and without E1:A226V mutation. Infect Genet Evol. 2013;20:396-406.

43. Bereczky-Veress B, Abdelmagid N, Piehl F, Bergstrom T, Olsson T, Skoldenberg $B$, et al. Influence of perineurial cells and toll-like receptors 2 and 9 on herpes simplex type 1 entry to the central nervous system in rat encephalitis. PLoS One. 2010;5:e12350. https:/doi.org/10.1371/journal.pone.0012350.

44. Sato A, Linehan MM, Iwasaki A. Dual recognition of herpes simplex viruses by TLR2 and TLR9 in dendritic cells. Proc Natl Acad Sci U S A. 2006;103: $17343-8$

\section{Submit your next manuscript to BioMed Central and we will help you at every step:}

- We accept pre-submission inquiries

- Our selector tool helps you to find the most relevant journal

- We provide round the clock customer support

- Convenient online submission

- Thorough peer review

- Inclusion in PubMed and all major indexing services

- Maximum visibility for your research

Submit your manuscript at www.biomedcentral.com/submit 